\title{
sciendo
}

Transport and Telecommunication, 2021, volume 22, no. 1, 39-52

Transport and Telecommunication Institute, Lomonosova 1, Riga, LV-1019, Latvia

DOI 10.2478/ttj-2021-0004

\section{ROBUST OPTIMIZATION OF BUS STOP PLACEMENT BASED ON DYNAMIC DEMAND USING META HEURISTIC APPROACHES: A CASE STUDY IN A DEVELOPING COUNTRY}

\author{
Meisam Ghasedi ${ }^{1}$, Mahyar Ghorbanzadeh ${ }^{2}$, Iraj Bargegol ${ }^{3}$ \\ ${ }^{1,3}$ Department of Civil Engineering, Faculty of Engineering, \\ University of Guilan, Rasht, Iran \\ ${ }^{1}$ meisam_ghasedi@msc.guilan.ac.ir, ${ }^{3}$ bargegol@guilan.ac.ir \\ ${ }^{2}$ Department of Civil and Environmental Engineering, FAMU-FSU College of Engineering, \\ Florida State University, Tallahassee, FL, USA \\ ${ }^{2}$ mghorbanzadeh@fsu.edu
}

\begin{abstract}
The operating condition of bus transit system has not been efficient in most cities of Iran, and many management methods such as regular bus scheduling, assigning exclusive bus lanes, etc., which are necessary for increasing the efficiency of this system, were not regarded enough. Thus, achieving a method for locating the bus stops and optimizing the number of such stops based on a nonhomogeneous spatial and temporal distribution of passengers as well as the local traffic patterns are important to be investigated. As such, the present study aims to investigate the modeling of a bus transit system corridor according to the non-homogeneous spatial and temporal distribution of passengers throughout the route aiming at optimization of the number of attracted passengers to the bus. For this purpose, the 8-km route from Vali-e-asr roundabout to Gas roundabout in the city of Rasht in the north of Iran is selected for modeling. Hammersley sampling method, as well as two heuristic optimization techniques, including a Genetic Algorithm (GA) and Particle Swarm Optimization (PSO) algorithm, are used for generating a non-uniform population and solving the optimization model. Therefore, the results of this analysis are compared to the optimization results by using the probabilistic analysis without considering the reference uncertainty. Finally, the PSO is selected as the superior algorithm for modeling and locating the bus stops due to its results in less travel time, and the validity of robust optimization model is shown due to its higher accuracy and adaptation to the real-world environment. Overall, although the optimization results based on indeterminate analysis in comparison to determinate analysis brought about more average travel time, more population sets were covered by the new introduced stops during 18 active hours of the bus transit system.
\end{abstract}

Keywords: optimization, bus stop placement, dynamic demand, GA, PSO

\section{Introduction}

Cities are considered as the gathering place of vital facilities and the main centers attracting the population due to the rapid growth of urbanism. The continuity of this process will lead to the high population density, especially in small cities. Meanwhile, traffic is one of the problems that people and officials are dealing with in big cities. Urban transport systems moved beyond the technical and engineering science and turned into a socioeconomic issue having different consequences for the society. Long traffic queues, shortage of parking space, overcrowding, traffic limitations in downtown, mental effects, air pollution, etc. made the transport managers and planners show more tendencies to mass transportation systems. Therefore, the need to use public transport systems is considered more than ever (Pojani and Stead, 2015). The development of public transportation system is one of the main tools of traffic management and reducing traffic density in urban environments. The optimal location of bus stops considering the non-homogeneous spatial and temporal distribution of passengers can be a part of the above-mentioned development. The lack of investment and inefficient organization of public transport in many provinces of Iran encourage people to use their personal cars. This could lead to an increase in motorized trips and reduce the capacity of roads, and consequently, it makes the cities more congested. Meanwhile, using the potential of a bus rapid transit could cover at least half of urban public transport demand, and this leads to less use of personal cars by people.

An initial look at the condition and number of the bus system in Rasht by 2018 showed that only one active bus is working in some bus routes while the maximum fleet size in Rasht is equal to 8 buses which were recently increased by 50 buses in late 2019 (Rasht Transportation Master Plan, 2018). As a result, the bus transit system in this city is not only successful in attracting more travel demand but also is moving away from the initial criteria for developing public transport systems. Thus, based on the rapid development of bus transit system in Rasht, the present study aims at presenting an accurate and comprehensive model to calculate the number of bus stops and travel time based on the dynamic and indeterminate nature of the number of attracted passengers to the bus transit system and present a robust model against reference uncertainty, that is nonhomogeneous spatial and temporal distribution of passengers at different hours in different days. 


\section{Research Background}

Bus stop placement is a complicated issue, and it depends on various parameters, so many studies have been done during the last years. Some of these studies mentioned that it is better to decrease stops as much as possible along a route to have a more efficient system and make a longer trip over a fixed period of time (Wirasinghe \& Ghoneim, 1981; Saka, 2001). However, reducing the number of stops will increase the walking distance for people and discourage them from using the public transportation system (Foda \& Osman, 2010; Murray, 2003). Hence, there is a crucial and challenging issue for transportation experts to make a balance between these components (Ibeas et al., 2010; Murray, 2003).

Considering the past studies and manuals, there is a wide range of values for bus stop spacing from 300 to $1800 \mathrm{~m}$ for city center areas (Wright and Hook, 2007). The spacing recommendation for European cities like Paris, London, Rotterdam, and Zurich is between 300 and $450 \mathrm{~m}$ (Van Nes and Bovy, 2000), while these distances for the United States is between 150 to 365 m (TCRP Report 19, 1996). There are different criteria for optimizing the number of stops in public transport systems such as the decrease of travel and waiting time, walking distance, and public transport costs which each of these criteria have been investigated separately over the past years in different studies (Ceder et al., 1983; Bowerman et. al., 1995; Vuchic and Newell, 1968; Fernandez, 1988) Meta-heuristic methods are used as modern methods for solving these problems. Such methods have high reliability due to their high accuracy and combining these methods with Geographic Information System (GIS) can increase the accuracy of the presented models to a great extent since the spatial properties are the inseparable component of public transport systems. Furth and Rahbee (2000) used a simple geographical model and dynamic programming algorithm to determine the optimal bus stops locations. They concluded that the model would result in better answers if the optimal distance of bus stops is closer to the European standard, and this distance must be changed from 200 to $400 \mathrm{~m}$. Murray (2001) used various spatial analytical techniques, including a location covering model to study the access to public transportation and its efficiency in Brisbane, Australia. He concluded that the use of public transport system could be increased by using commercial geographical information system integrated with the developed strategic analysis approach. Lao and Liu (2009) used the Data Envelopment Analysis (DEA) and GIS to study the functional efficiency and spatial coverage of the bus transit system. They computed the operational efficiency and spatial effectiveness of a public transit system. Delmelle et al., (2012) combined a metaheuristic method and geographical information system to increase the efficiency of bus system as well as improving the accessibility of stops. Simulated annealing heuristic is used to solve the optimization model due to its non-linearity.

Despite the considerable attention paid to the location of bus stops with the aim of determining the optimal number of stops, a relatively less effort is made for solving this problem according to the dynamic nature of the factors affecting the travel time. Peng and Zhu (2013) proposed a multiple objective programming model considering maximum railway department revenue to give the maximum service to passengers and impose less total cost to them. By considering the passenger flow dynamic assignment, they proposed a model which solved a multi- objective programming model by using the genetic algorithm. Bai et al., (2014) presented a model which simultaneously considered the dynamic distribution of passenger flow and spatial average loading ratio throughout the route. Their model can balance the service level at all bus stops and improve the bus company profit. Barrena et al., (2014) investigated the design and optimization of train timetable based on dynamic demand with the objective of minimizing the average passenger waiting time. They used two mathematical programming formulations, which generalize the non-periodic train timetabling problem under a dynamic demand pattern. Their model demonstrated the superiority of adaptive large neighborhood search metaheuristic compared to a truncated branch-and-cut algorithm by reduction to $26 \%$ in passenger waiting times. Otto and Boysen (2014) optimized the location of bus stops by using three algorithms of genetic, annealing, and dynamic programming to maximize its coverage for access to customers. They presented a two-step dynamic program based on maximum covering location problem in networks (MCLPN) heuristic methods by using the current network information. The results showed that their heuristic methods would present optimal solutions for $87 \%$ of problems. Tirachini (2014) considered the interplay between bus stop size, bus running speed, spacing, and congestion in the routes with the high demand of passengers. He showed that the Poisson models used in bus stop placement process caused the underestimation in the optimal number of bus stops. Finally, he concluded that if the demand rate increases, by assuming the constant bus speed, the distance between the bus stops must be reduced. Meanwhile, if both factors of bus speed and boarding time speed of passengers will increase, the distance between bus stops should be kept long even at the high demand of passengers. Jamili and Aghaee (2015) presented an uncertainty-immunized solution by using the robust optimization model as a new method as well as a decomposition based and simulated annealing algorithm for determining the optimal train timetable pattern. Gerami Matin et al., (2017) used robust metaheuristic algorithms to reach optimal road maintenance planning. They showed the superiority of multi- 
objective algorithms over single objective algorithms in the mentioned problem by using non-domination sorting genetic algorithm II (NSGAII) and multi-objective particle swarm optimization.

Bargegol et al., (2017) developed a new formula for calculating the travel time and modeling an exclusive bus lane corridor. They optimized the number of stops and distance between them at peak hour by using the multi- objective genetic algorithm. Since in their study, they considered the distribution of passenger flow at peak hour as the basis for bus stop placement and optimization of their number, the present study aimed at solving the bus stop placement problem by considering the dynamic distribution of passengers during 18 active hours of the bus transit system.

\section{Methodology}

In this paper, by using total travel time formula (Bargegol et al., 2017), the travel time and optimal number of stops can be calculated by considering the non-homogeneous spatial and temporal distribution of passengers during 18 active hours of the bus transit system. Hence, based on the dynamic and indeterminate nature of the number of attracted passengers to bus transit system during different days, a robust optimization model is used for solving this problem. For this purpose, to generate a non-uniform population sets and solve the optimization model, Hammersley sampling method, as well as two heuristic algorithms, including a GA and PSO will be used. Finally, the results of this analysis will be compared to the optimization results without considering the reference uncertainty (non-homogeneous spatial and temporal distribution of passengers at different hours in different days) by using the probabilistic analysis.

\section{Corridor characteristics and related assumptions}

There is only one available ring road from three predicted ring roads in the transportation master plan of Rasht, which is incompletely serving the passing traffic in this city. Therefore, the route shown in Figure 1, which is 8 kilometres in length and has a circular pattern, is selected as one of the appropriate routes for constructing an exclusive bus lane to facilitate the public transport needs without the need for passengers to enter the high congested areas.

Since there is traffic interference with other flows in several parts of suggested bus exclusive lanes in Rasht, the present study aimed at modeling a corridor with circular pattern and less traffic interference in comparison to other routes. According to the long distance of the route and several access points placed on both sides of this route, a half of this proposed ring (the distance between Gas and Vali-e-asr roundabout) is selected for modeling which is shown in Figure 1. The studied route begins from Gas roundabout and reaches to Vali-e-asr roundabout after passing $8 \mathrm{~km}$ and several intersections. Thus, this $8-\mathrm{km}$ route is divided into 80 cells, and the population set is distributed among these 80 cells. It should be noted that the surrounding lands are commercial, administrative and residential and the cells around intersections attract more passengers.

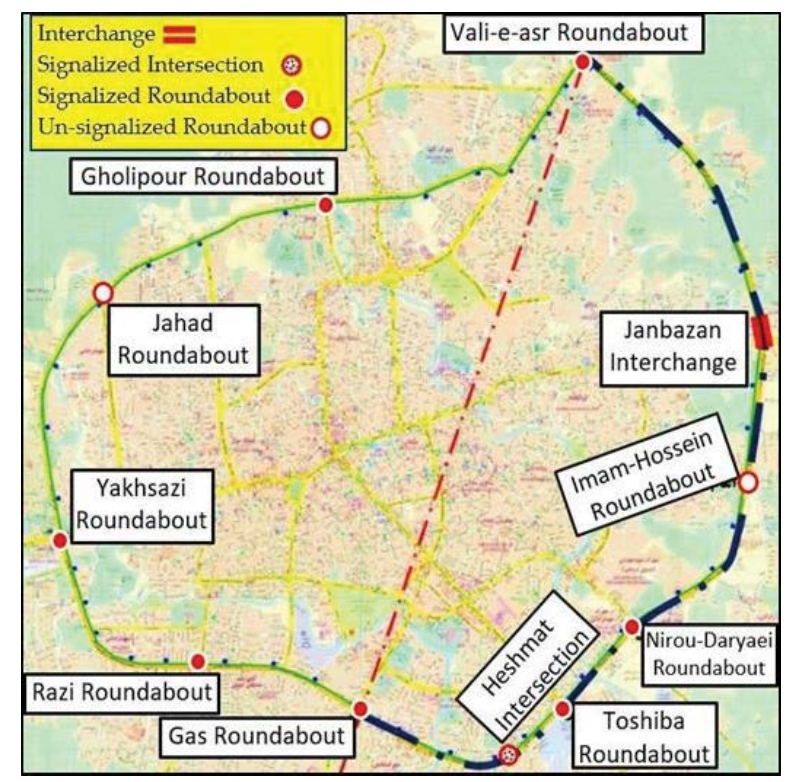

Figure 1. The study area 
The exact number of the motorized trips in all 24 hours of day is extracted from the city of Rasht transportation master plan to make the origin-destination (O-D) matrix in the desired route. Thus, firstly the number of motorized trips, which made in this route at the peak hour and during 18 active hours of the bus transit system, must be separately calculated to make the desired O-D matrixes. Then, based on this population distribution, a more accurate matrix of daily motorized trips in terms of the trip hour around the studied corridor can be obtained. Since the people interest rate of using bus transit system in Rasht is about $15 \%$ and the ideal value of this percentage according to the Rasht transportation experts opinions is 45\% (Rasht Transportation Master Plan, 2018), it is assumed in modeling that an average of 30\% of people use bus system for traveling in this corridor. By calculating the total number of trips between the traffic areas located around this corridor and calculating 30\% contribution of bus transit system in displacing the passengers, 1437 trips are made at the peak hour and 8982 trips are made during 18 active hours of the bus transit system.

At least six buses are used for serving at the peak hour in the corridor by considering the level of service A for urban transport services (Highway Capacity Manual (HCM), 2010). Obviously, this number of bus can vary by considering different capacities for different busses and serving hours. The required time for walking from the origin to the corridor of bus exclusive lane will not be included in the calculations because it is constant in case of selecting any other vehicle and only the walking time of passengers along the route will be important. The criterion for selecting a bus stop by passengers is to achieve it in the shortest possible time. When the passengers enter a point just between the two stops, the previous stop would be chosen. It is also assumed that passengers will not use the bus for the distances of less than three cells. Thus, the number of trips made from each cell to the next two cells will be zero. Moreover, boarding and alighting the passengers is done simultaneously through two separate doors which are 2 individuals for each of them. As it is mentioned before, since the desired route is an exclusive lane, thus no delay caused by stopping in traffic jam, but because of three signalized intersections, redlight time should be added to total travel time due to stopping behind the signals at the intersections (Bargegol et al., 2017)

\section{Optimization by GA and PSO algorithms}

\subsection{Design variables}

To analyze this route, its length is divided into 100 meters long cells, and there are 80 cells along the route. The cells known as 1, 18, 26, 42, 52 and 80 are placed at intersections. It is assumed that in this route except for the first and last stops, the remaining stops are located 500 meters apart (five cells) from each other. So, the cells known as $1,6,11,16,21,26,31,36,41,46,51,56,61,66,71,76$ and 80 are the main assumed stops as design variables (Bargegol et al., 2017).

\subsection{Objective function}

The objective function in this problem is to minimize the travel time (Bargegol et al., 2017). Eq. (1)

$T=P\left(\frac{\overline{d_{P}}+\overline{d_{A}}}{v_{p}}+\frac{\bar{d}}{V}+\frac{h-60}{2}\right)+\mathrm{B} \sum_{n=1}^{Q} T_{l_{n}}+\mathrm{B} \sum_{n=1}^{Q} T_{l^{\prime}{ }_{n}}+T_{\mathrm{R}}$.

$\mathrm{T}=T_{i}+T_{o}$.

$T_{o}=T_{1}+T_{2}+T_{3}$.

$T_{i}=T_{4}+T_{5}+T_{6}+T_{\mathrm{R}}$.

$T_{1}=\frac{P \times \overline{d_{P}}}{v_{p}}$.

$T_{2}=\frac{A \times \overline{d_{A}}}{v_{p}}$.

$T_{3}=P \times \frac{h-60 s}{2}$.

$T_{4}=\frac{P \times \bar{d}}{v}$.

$T_{5}=\mathrm{B} \sum_{n=1}^{Q} T_{l_{n}}$. 


$$
\begin{aligned}
& T_{6}=\mathrm{B} \sum_{n=1}^{Q} T_{l^{\prime} n} . \\
& T_{l_{n}}=\left[\left(\sum_{z=1}^{n} P_{z}-\sum_{z=1}^{n} A_{z}\right) / B\right] \times \operatorname{Max}\left[1 / K_{a}\left(P_{a} T_{a} / B\right), 1 / K_{b}\left(P_{b} T_{b} / B\right)\right]+\frac{1 / K_{a} \sum_{0}^{p a}\left(T_{a}\right)}{B} . \\
& T_{l^{\prime} n}=\left[\left[\sum_{z=1}^{n-1} P_{z}-\sum_{z=1}^{n-1} A_{z}\right] \times T_{d} / 2\right] /_{B}+\left[\left[\sum_{z=1}^{n} P_{z}-\sum_{z=1}^{n} A_{z}\right] \times T_{d} / 2\right] / /_{B} .
\end{aligned}
$$

$T_{o}:$ Passengers elapsed time out of the bus.

$T_{i}$ : $\quad$ Passengers elapsed time in the bus.

$T_{1}$ : Passengers walking time from origin to stop.

$T_{2}$ : Passengers walking time from stop to destination.

$T_{3}$ : Passengers waiting time in stop (Assumingrange of passengers waiting time at each stop $=0,1,2, \ldots, 9 \mathrm{~min})$.

$T_{4}$ : Passengers in-vehicle travel time along the route.

$T_{5}$ : Passengers wasted time because of alighting and boarding time.

$T_{6}$ : Passengers wasted time because of acceleration and deacceleration (considering different forms of payment).

$T_{\mathrm{R}}$ : Red-light time along the route.

P: Total demand in one hour. It is obtained from the origin-destination matrix arrays of the travel.

$d_{P}$ : The passenger average walking distance from origin to stop. Its amount is obtained by dividing passenger total walking distance from each cell up to the cell including the corresponding stop by the total number of trips in one hour. $(\mathrm{m})$

$d_{A}$ : The passenger average walking distance from the cell consisting of the destination stop to the destination cell. Its amount is obtained by dividing passenger total walking distance from the stop to the destination by the total number of trips in one hour. $(\mathrm{m})$

$v_{P}$ : The passenger average walking speed on bus route. $(\mathrm{m} / \mathrm{s})$

$d$ : The average distance travelled by passengers by the bus. Its amount is obtained by dividing total amount of distance of the cell consisting of the origin stop to the cell consisting of destination stop by the total number of trips in one hour.

$V$ : The average speed of bus. $(\mathrm{m} / \mathrm{s})$

$h$ : Headway of buses. $\mathrm{h} \leq 600 \mathrm{~s}$ (Assuming range of passengers waiting time at each stop $=0,1,2, \ldots, 9 \mathrm{~min}$ ).

$B$ : The number of buses that could pick up all the passengers in an hour. $(\mathrm{B} \geq 6)$.

$T_{l_{n}}$ : The wasted time caused by alighting and boarding of passengers at the stop $\mathrm{n}$. (s

$T_{l^{\prime} n}$ : The wasted time due to the increase and decrease of the bus speed at the stop n.(s)

$\sum_{z=1}^{n} P_{z}$ : The sum of passengers boarded the bus to the stop $\mathrm{n}$.

$\sum_{z=1}^{n} A_{z}$ : The sum of passengers alighted from the bus to the stop $\mathrm{n}$.

$P_{b}$ : The number of passengers that boarded the bus at the stop $\mathrm{n}$.

$P_{a}$ : The number of passengers that alighted from the bus at the stop $\mathrm{n}$.

$T_{b}$ : The time required for each passenger to board the bus. (s)

$T_{a}$ : The time required for each passenger to alight from the bus. (s)

$K_{b}$ : Number of passengers boarding the bus simultaneously.

$K_{a}$ : Number of passengers alighting from the bus simultaneously.

Q: Number of stops.

$T_{d}$ : Dead time per stop (s).

\subsection{Modeling and optimization process}

The algorithm procedure is that firstly the model received the O-D matrix as input. Due to the 8$\mathrm{km}$ length of the route, it is divided into 80 cells. The arrays of the matrix will be the number of trips made from the origin cells to the destination cells. This matrix is separately introduced for design mode based on the peak hour trips in an Excel file and then generated by the software for the design mode based on 18 active hours of bus transit system. The population generation process is that 18 different population sets are generated based on the trips percentages allocation to different hours in a day which is obtained from Rasht transportation master plan. The cells near the intersections have a higher probability for attracting the passengers flow. After receiving the input (O-D matrix), the software generates the initial population for solving the optimization problem. Initial population refers to the different number of 
bus stops throughout the route which is different according to the type of used algorithm and finally, the travel time is calculated by using the introduced objective function. Then, the best placement for each mentioned combination of bus stops is introduced as the optimal placement (Bargegol et al., 2017).

The flowchart of optimization process by PSO and GA algorithms are shown in Figure 2 and Figure 3. It should be noted that the number of defined generations for repetition is the stop criteria in the optimization process.

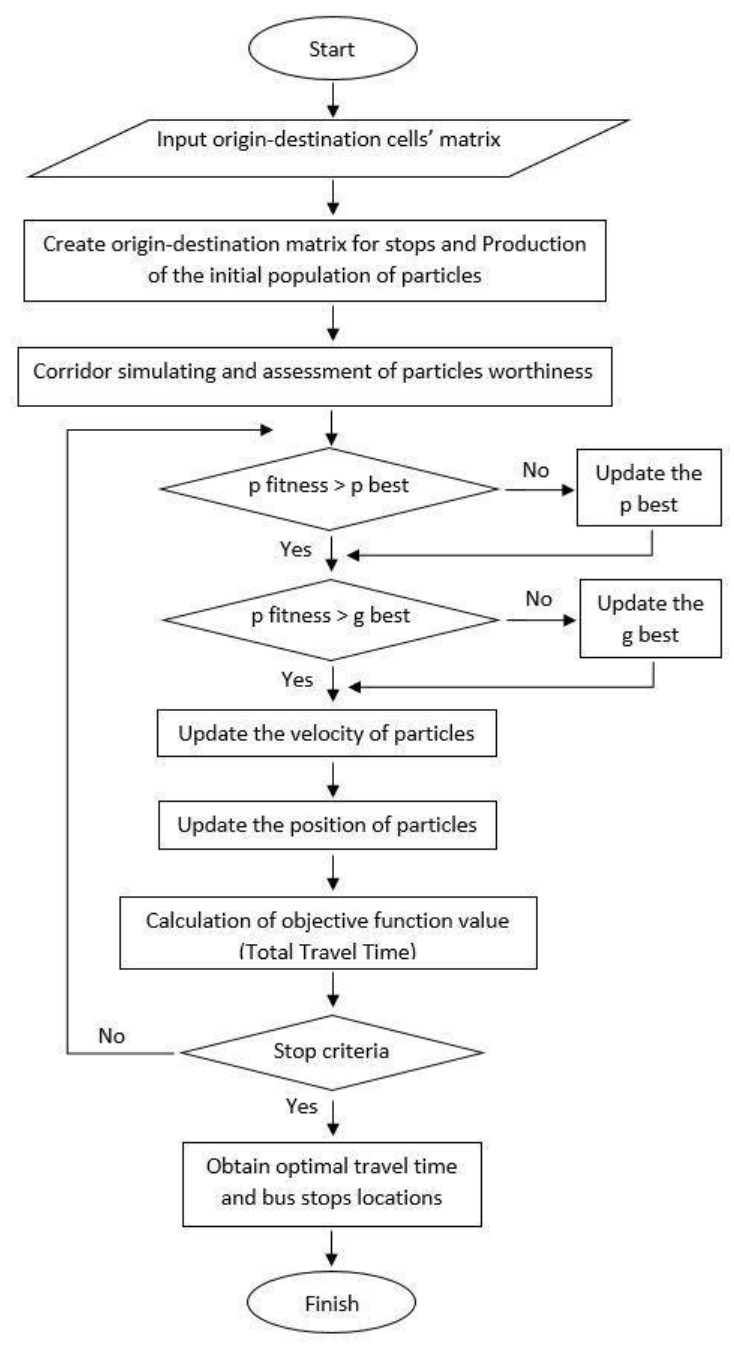

Figure 2. Conceptual flowchart of optimization process by PSO

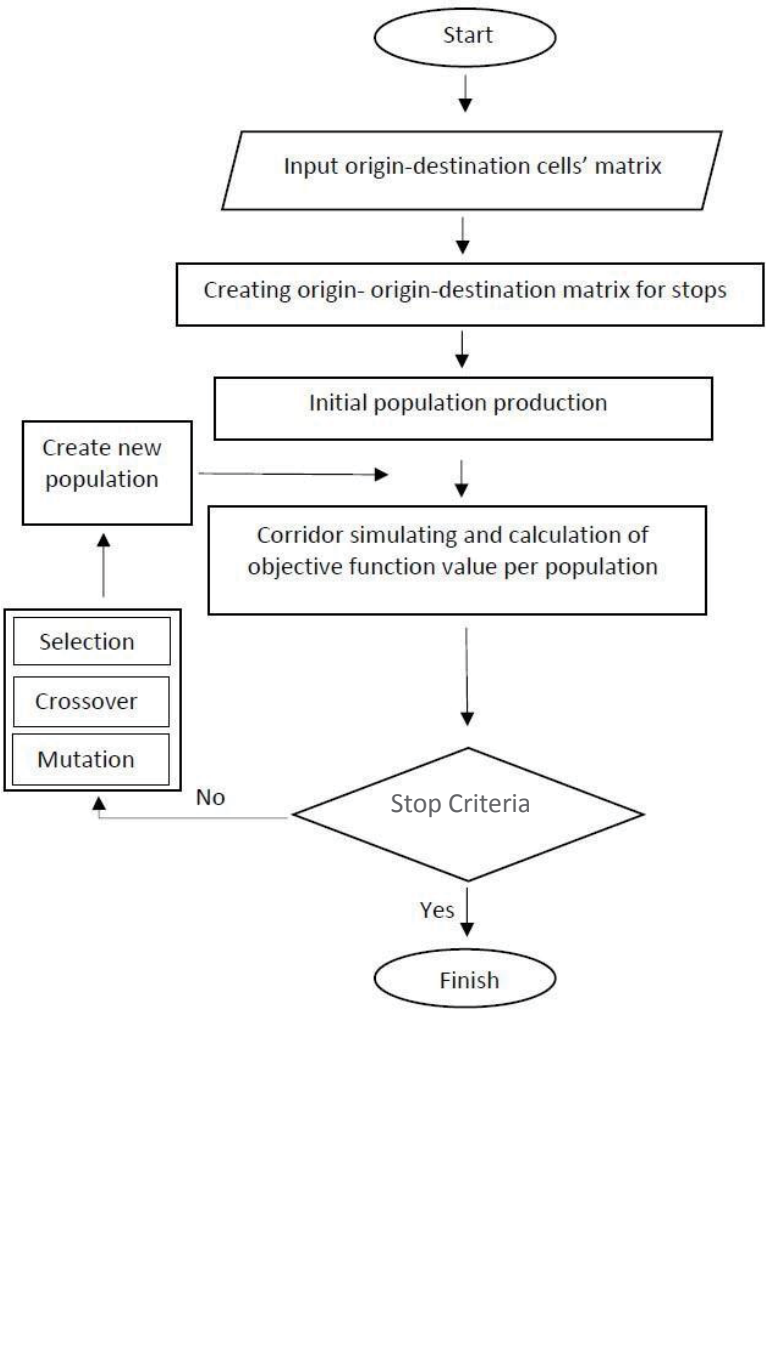

Figure 3. Conceptual flowchart of optimization process by GA

\subsection{Optimization process using uncertainty analysis}

The concept of robustness in an optimization problem can be explained by the optimization imperfections without considering the uncertainty. When the optimization process is performed without considering the uncertainty of some parameters, it may not lead to reaching the best available answers. In the optimization problem of bus stops placement, when the population is distributed constantly, a solution will be applicable just for that set of population. However, when the population distribution among the cells is made with a probability density function around the initial population set, an optimal solution will be achieved that works for different population sets. To insert an uncertainty in the problem, 20 different population sets higher and lower to the initial population set are created by Hammersley sampling method, and the optimization process is performed for those population sets, unlike the first mode that is conducted just for one population set during 18 active hours of bus transit system. Finally, population sets are generated for two modes of determinate and indeterminate design mode in large scale $(\mathrm{N}=10000$ samples) by using the probabilistic analysis method to show the difference more obvious between these two approaches. 


\section{Result analysis}

The process of bus stop placement in terms of time could be investigated by two methods. In the first method, the peak hour is selected for generating the passengers flow O-D matrix, while in the second method which is used in this study, the peak hour is not considered and the optimization process is performed for the 18 active hours of the bus transit system. It should be noted that the peak hour must be typically considered as the basis of design and optimization process. Due to a dynamic and indeterminate nature of the number of attracted passengers to bus transit system and the nature of robust analysis requiring a lot of data for presenting a more accurate model, the need to use the number of trips made in 18 active hours instead of peak hour is understandable. The results obtained from optimization by GA considering peak hour and 18 active hours of bus transit system are shown in Figure 4(a) and Figure 4(b). The average travel time has an approximate 2-min difference in two modes of design in the studied route when the bus capacity increases from 45 to 135 passengers at the peak hour by considering the other parameters remain constant. Obviously, in case of not using the busses with higher capacity at the peak hour, the system will not be usable for all passengers and the passengers level of service in the bus will significantly decrease with the increase of the number of standing passengers in a bus up to the saturation level.

Another significant point obtained from comparing these two figures showed that the slope of Pareto chart at the design mode based on the peak hour is a little steeper than the design mode based on the 18 active hours of a day. In other words, an optimal design can be achieved at the peak hour with a significant reduction in the number of bus stops and a slight increase in travel time.

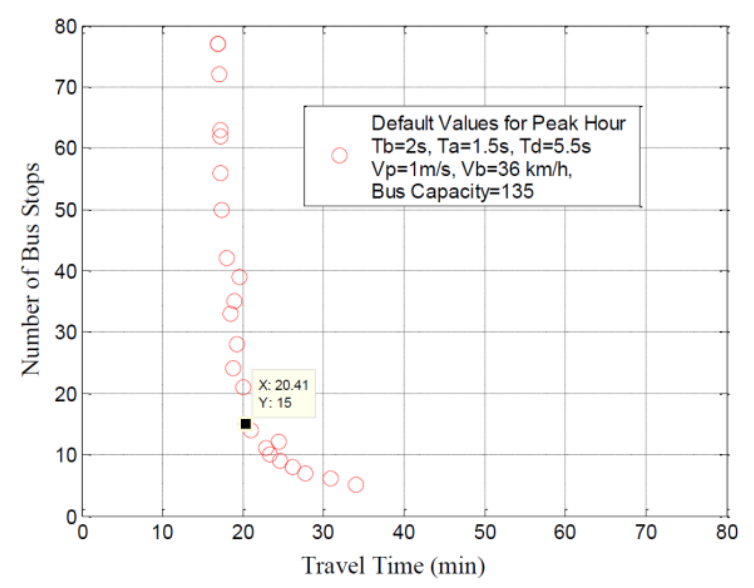

(a) Based on peak hour

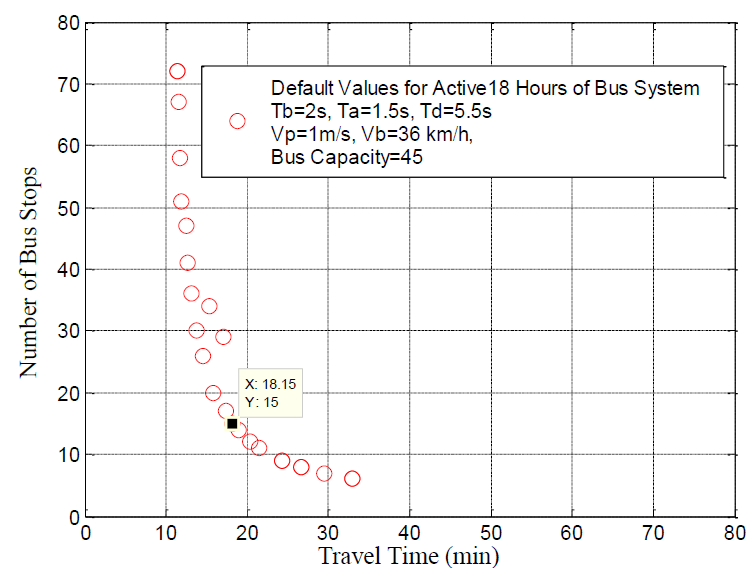

(b) Based on 18 active hours of bus transit system

Figure 4. Two modes of optimization by GA

After comparing the process of bus stops placement based on two criteria of the peak hour and 18 active hours of bus transit system, now the results of optimization based on 18 active hours of bus transit system using GA and PSO algorithms can be compared for recognizing the superior algorithm.

\subsection{The factors affecting the travel time}

The impact of different factors affecting the travel time (boarding time, alighting time, bus average speed, pedestrian speed, bus capacity, and dead time per stop) are investigated by using two heuristic algorithms including a GA and PSO. It should be noted that default values used in relations are obtained from local traffic information considering the reference values (TCRP Report 19, 1996; Ceder, 2007). As it can be seen in Figures 5(a) and 5(b), the optimization process with the PSO algorithm in all modes leads to less travel time for an equal number of stops and make more stable and regular answers. It is worth mentioning that the mutation of GA leads to more unstable responses during different optimization running processes in software. Figure 6 shows the difference between using GA and PSO algorithms more clearly by considering 15 stops as an optimal number of stops. 


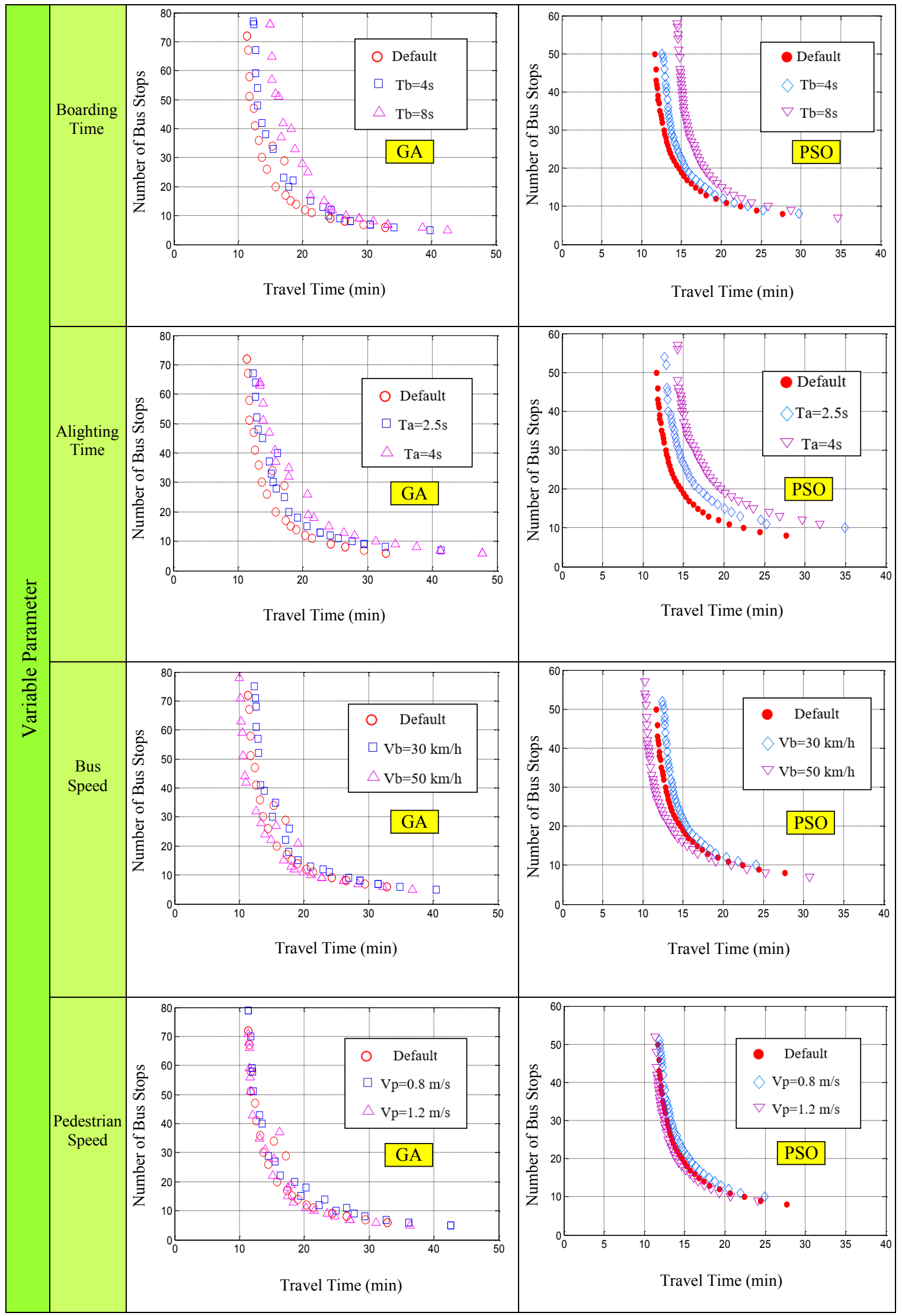

Figure 5(a). The effect of different factors on travel time using GA and PSO 


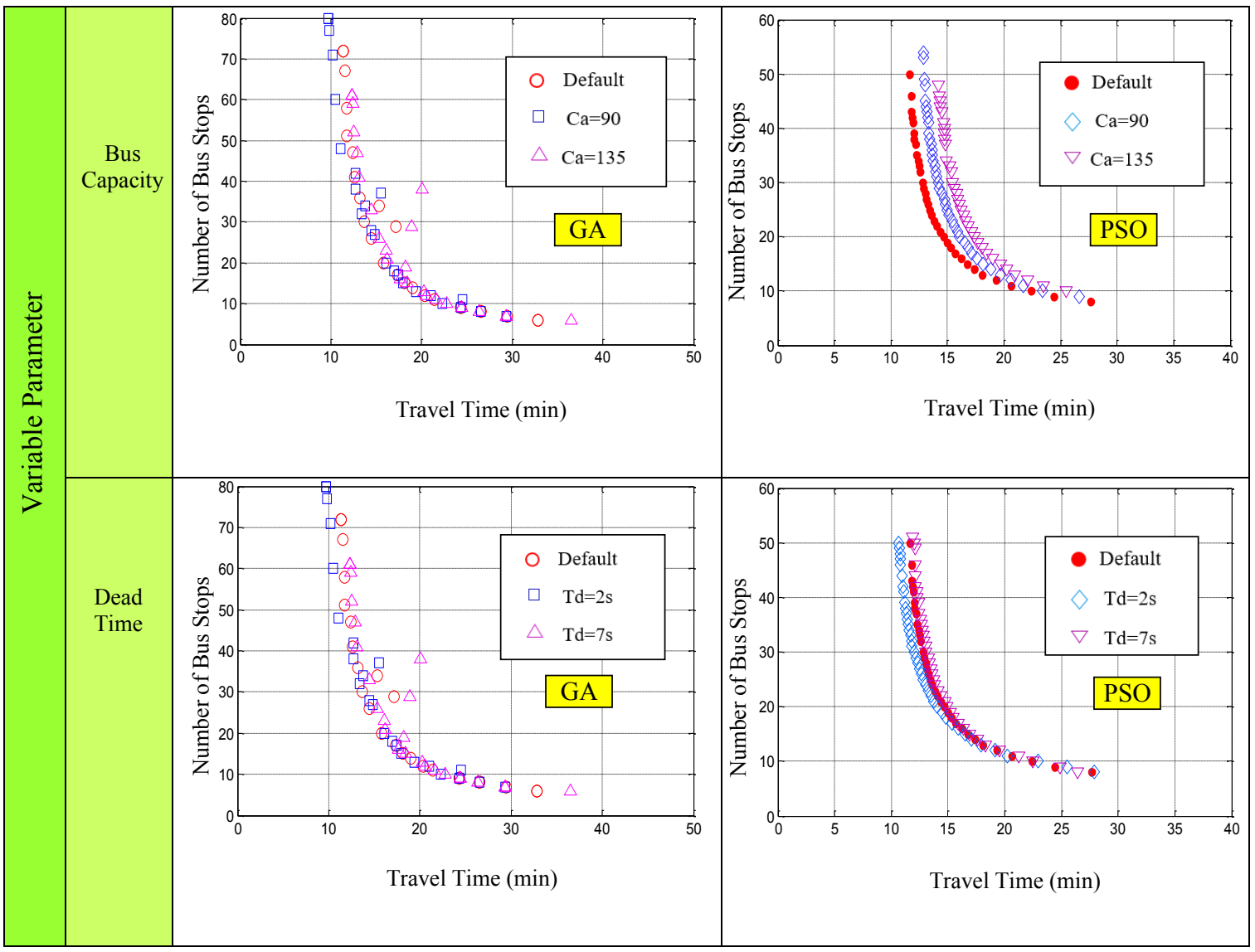

Figure 5(b). The effect of different factors on travel time using GA and PSO

As it can be seen in Figure 6, comparing the effective factors on travel time, in summary, shows that changing boarding and alighting time has the most effect on total travel time in optimization process by using both GA and PSO algorithms. Thus, less travel time and more passenger satisfaction with bus transit system can be achieved by reducing the boarding and alighting time using the buses with wider doors and intelligent payment system as well.

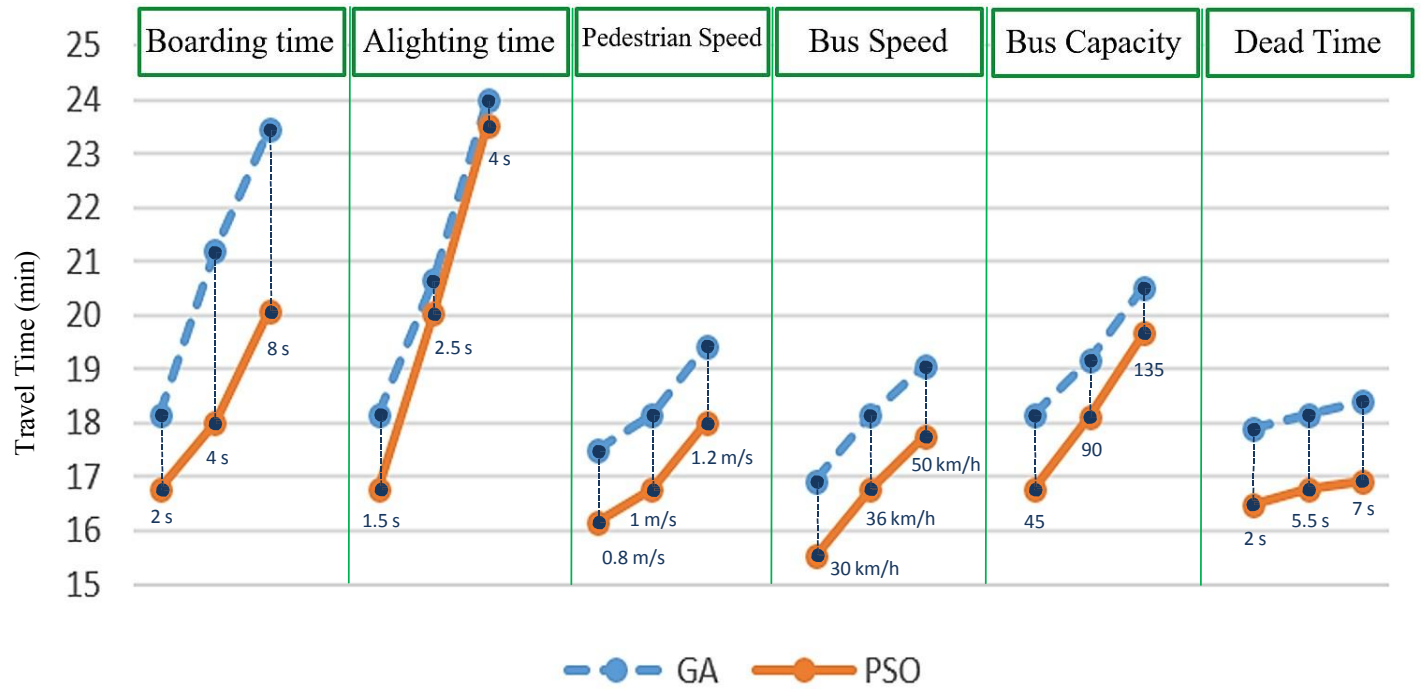

Figure 6. Comparing effective factors on travel time in summary 


\subsection{Selecting the superior algorithm}

As it can be seen in Figure 5, the optimization process with the PSO algorithm in all modes presents less travel time for an equal number of stops. By considering the default values, the average travel time is 18.15 minutes by using the GA while the travel time reduces about 1.5 minutes in case of using PSO algorithm. Obviously, the difference between these two algorithms will be more tangible by studying a longer corridor with higher passenger flow distribution. Thus, the PSO is selected as the superior algorithm for making the robust model against uncertainties.

The obtained bus stop locations using GA and PSO algorithms can be observed in Table 1 without considering the uncertainty:

Table 1. The obtained bus stops cells (without considering the uncertainty)

\begin{tabular}{|l|l|l|}
\hline Algorithm & Cells Numbers of Stops & Average Travel Time (min) \\
\hline GA & $1-8-14-27-32-36-43-52-56-58-63-68-70-77-80$ & 18.15 \\
\hline PSO & $1-8-18-26-32-36-41-46-53-58-61-66-71-74-80$ & 16.76 \\
\hline
\end{tabular}

\subsection{The results of the uncertainty analysis}

In order to achieve a robust model against uncertainty, it is necessary to consider the dynamic or indeterminate nature of parameters in solving the optimization problem. In the present study, the considered uncertainty is the non-homogeneous spatial and temporal distribution of passengers at different hours of different days. Figure 7 shows the total generating trips during 18 hours a day divided by cell numbers. As it is mentioned earlier, the Hammersley sampling method is used for generating a non-uniform population to make 20 different population sets higher and lower to the initial population distribution. Finally, the optimization process is performed for these population sets with GA and PSO.

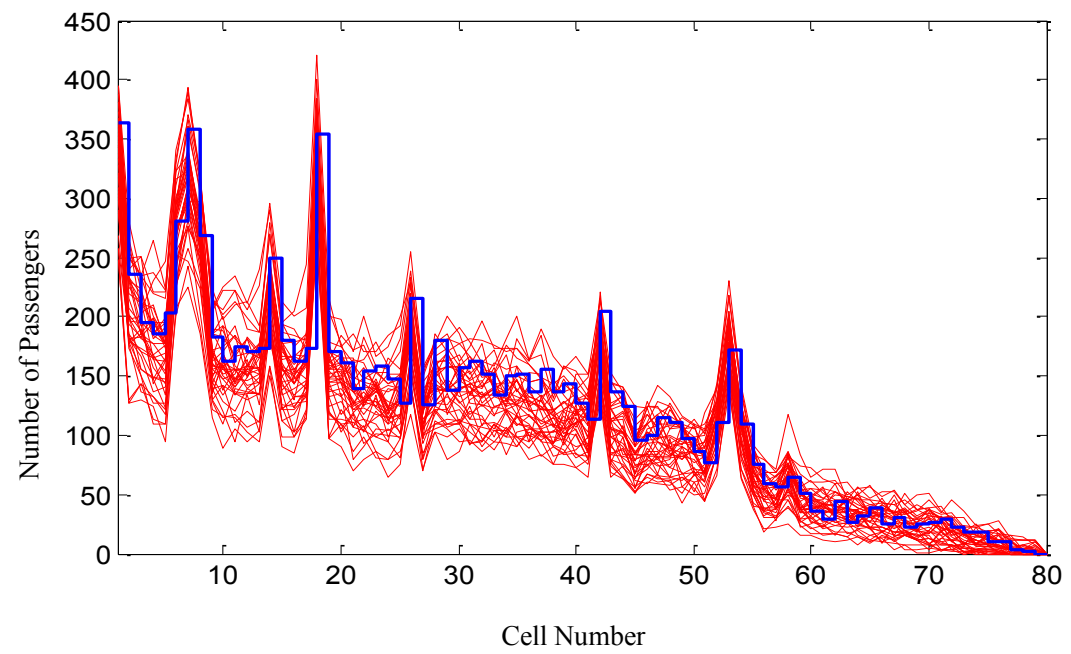

Figure 7. Distribution of generating trips around the initial population distribution in 18 hours

By considering the population tolerance observed in Figure 7, the robust optimization model can be achieved. After the optimization process, the location of bus stops obtained by GA and PSO algorithms by considering the uncertainty can be observed in Table 2 .

Table 2. The obtained bus stops cells (considering the uncertainty)

\begin{tabular}{|l|l|l|}
\hline Algorithm & Cells Numbers of Stops & Average Travel Time (min) \\
\hline GA & $1-8-18-24-38-40-41-43-48-52-58-63-68-72-76-80$ & 20.24 \\
\hline PSO & $1-7-14-18-26-29-34-39-42-46-52-57-64-68-76-80$ & 18.63 \\
\hline
\end{tabular}




\subsection{Validation of the robustness of results}

\subsubsection{Probability Density Function figures}

PDF and CDF figures, which are obtained by probabilistic analysis, showed the distribution of frequency for the obtained travel times using robust and ordinary optimization processes. By considering these figures, the eligibility of robust design method could be demonstrated.

PDF Figure 8 and Figure 9 show the percentage of different covered population sets based on travel time, which is 10000 sets in this problem using ordinary and robust optimization with GA and PSO.

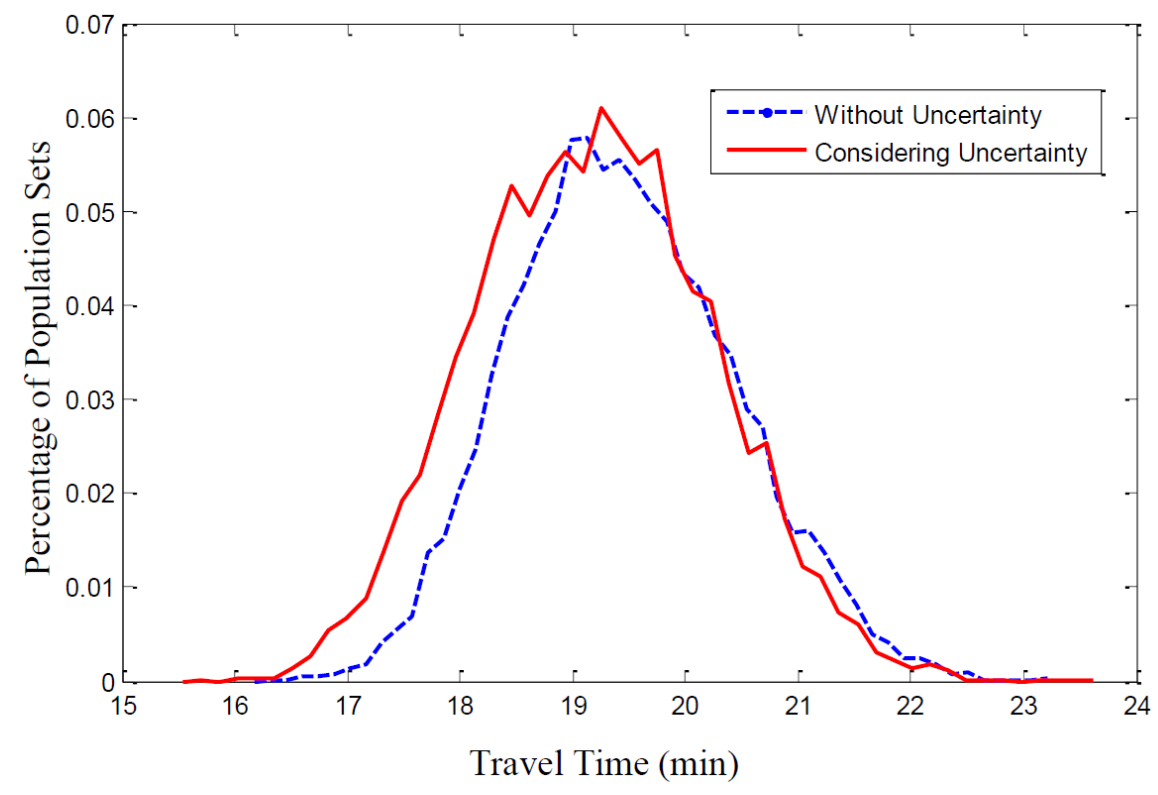

Figure 8. PDF of the frequency distribution for travel time (GA)

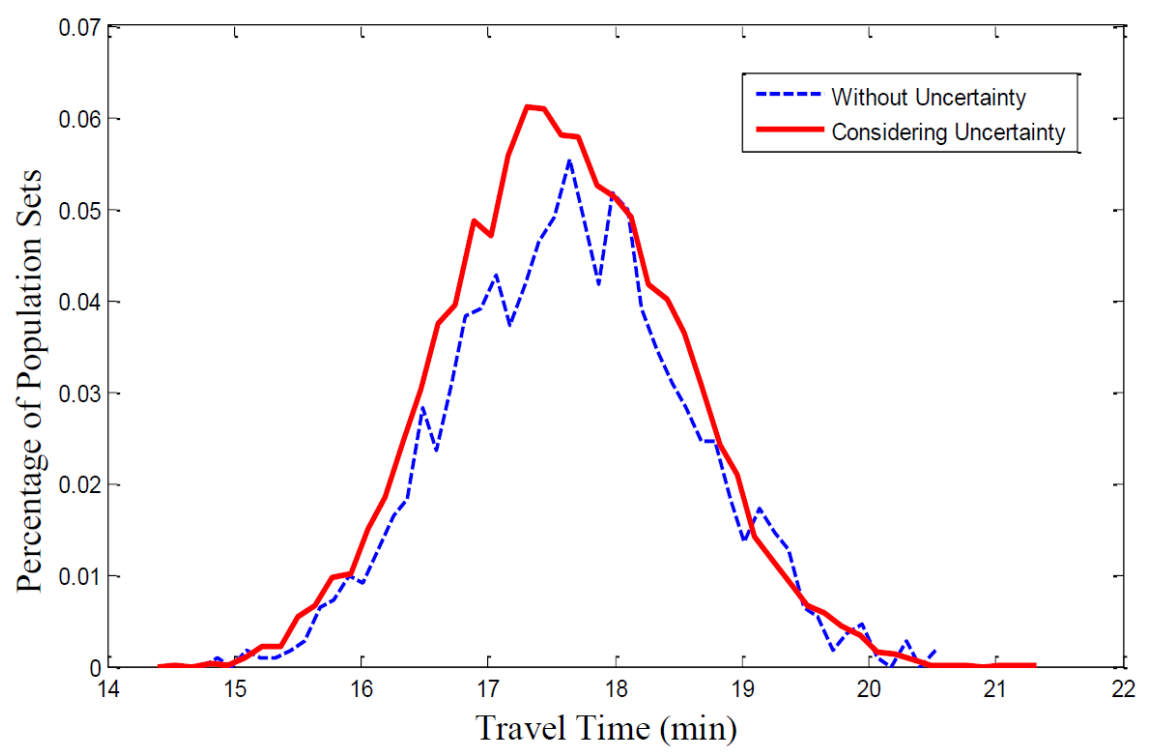

Figure 9. PDF of the frequency distribution for travel time (PSO)

\subsubsection{Cumulative Distribution Function figures}

CDF figure is used for comparing the two design methods more accurately indicating the cumulative percentage frequency of population sets based on travel time obtained by the GA and PSO 
algorithms. Although the travel time obtained from indeterminate design increases two minutes by considering the reference uncertainty, the model can respond to more different population sets. As it can be seen in Figure 10, about 1500 samples of 10000 different population sets are covered by the robust design model using GA by 18 minutes of travel time. Meanwhile, this number is about 750 without considering the uncertainty. In addition, as it can be seen in Figure 11, considering the PSO for design, by 18 minutes of travel time, about 9000 samples of 10000 different population sets are covered by the robust design model. Meanwhile, this number is 7000 for design mode without considering the uncertainty.

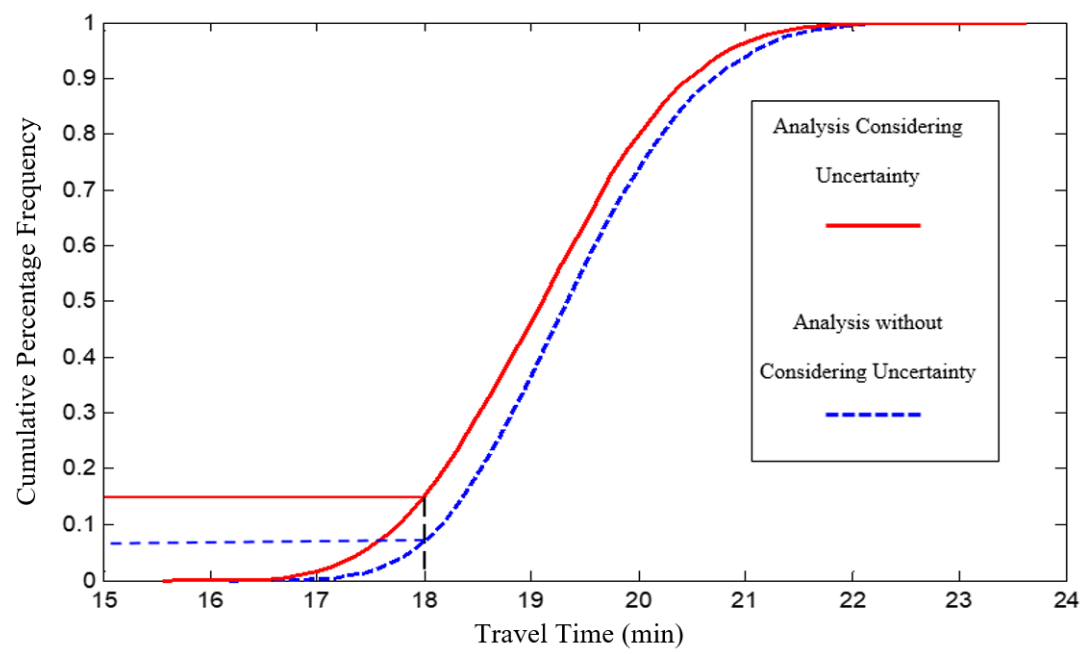

Figure 10. The cumulative frequency of passengers in 18 active hours of bus transit system (GA)

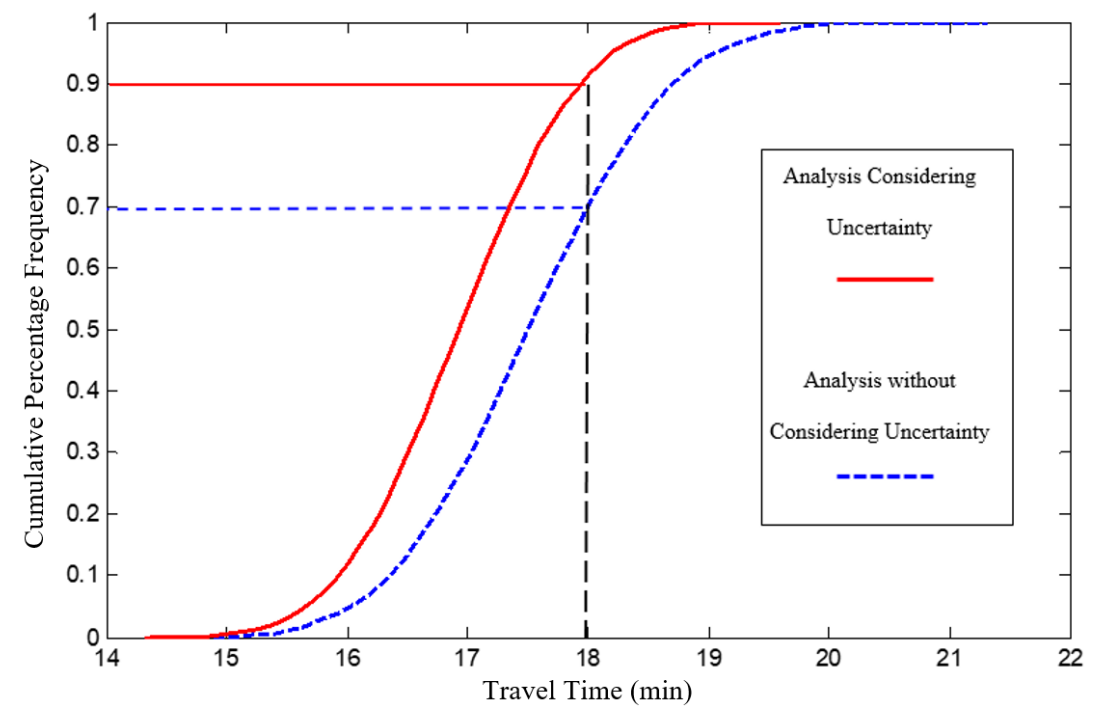

Figure 11. The cumulative frequency of passengers in 18 active hours of bus transit system (PSO)

Due to the coverage of more number of 10000 population sets by the optimization model, which considers the reference uncertainty, this model is selected as the superior model. In other words, although the optimization results based on indeterminate analysis in comparison to determinate analysis brought about more average travel time, more population sets were covered by the new introduced stops during 18 active hours of the bus transit system. Thus, the locations obtained from indeterminate design using the PSO algorithm, which is considered as the superior algorithm in design due to causing less travel time, are introduced as the final locations of the desired stops in the corridor. Figure 12 shows the location of bus stops throughout the route. Last but not least, this study's findings would definitely be stable conclusions and applicable to the other bus stop placement problems. 


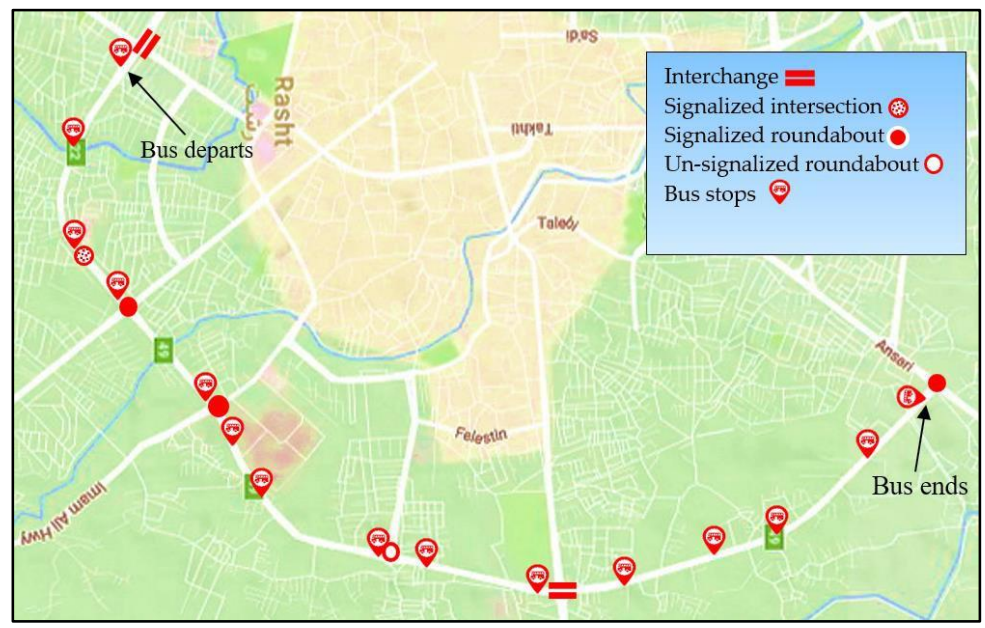

Figure 12. Location of bus stops by using a superior design method

\section{Conclusion}

In this study, the bus stop location problem was investigated based on a non-homogeneous spatial and temporal distribution of passengers on a route with an $8 \mathrm{~km}$ length located in the city of Rasht. For this purpose, two heuristic optimization techniques, including GA and PSO algorithms, were used for modeling and optimization due to the complex nature of stops placement in public transport system. The Pareto charts, which were shown in section 6 , allow for obtaining balanced solutions for the transit system, which is the optimal number of stops. Based on the obtained results, it can be concluded that the obtained bus stops locations using PSO algorithm leads to less travel time in comparison to the GA. The superiority of the PSO algorithm in a higher range of default values will be more obvious. Moreover, the bus stop placement was done by considering uncertainty in population distribution to achieve a robust model against reference uncertainty and regarding the indeterminate and dynamic nature of its real-world problem. Although the optimization results based on the indeterminate analysis in comparison to determinate analysis leads to more travel time, the probabilistic analysis showed that the locations of introduced stops by indeterminate analysis method is suitable for more population sets. In other words, the location of bus stops obtained by indeterminate analysis have been introduced based on more realistic and have more reliability in comparison to determinate analysis. This approach includes the dynamic nature of passenger flow distribution during the day, which is inevitable in the real world and provides the robust concept of this model.

\section{References}

1. Pojani, D., Stead, D. (2015) Sustainable urban transport in the developing world: Beyond megacities. Sustainability, 7(6), 7784-7805. DOI: 10.3390/su7067784

2. Transportation and Traffic Organization. (2018) Rasht Transportation Master Plan.

3. Federal Transit Administration. (2009) Characteristics of Bus Rapid Transit for Decision-Making. U.S. Department of Transportation

4. Wirasinghe, S. C., Ghoneim, N. S. (1981) Spacing of bus stops for many to many travel demand. Transportation Science, 15(3). 175-293. DOI: 10.1287/trsc.15.3.210

5. Saka, A. A. (2001) Model for determining optimum bus stop spacing in urban areas. Journal of Transportation Engineering, 127(3), 195-199. DOI: 10.1061/(ASCE)0733-947X(2001)127:3(195)

6. Foda, M. A., Osman, A. O. (2010) Using GIS for measuring transit stop accessibility considering actual pedestrian road network. Journal of Public Transportation, 13(4), 23-40. DOI:10.5038/2375-0901.13.4.2

7. Murray, A. T. (2003) A coverage model for improving public transit system accessibility and expanding access. Annals of Operations Research, 123, 143-156. DOI:10.5038/2375-0901.13.4.2

8. Ibeas, A., dell'Olio, L., Alonso, B., Sainz, O. (2010) Optimizing bus stop spacing in urban areas. Transportation Research Part E: Logistics and Transportation Review, 46(3), 446-458. DOI: 10.1016/j.tre.2009.11.001

9. Murray, A. T., Wu, X. (2003) Accessibility trade-offs in public transit planning. Journal of Geographical Systems, 5(1), 93-107. DOI:10.1007/s101090300105 
10. Wright, L., Hook, W. (2007) Bus Rapid Transit Planning Guide, New York: Institute for Transportation and Development Policy.

11. Van Nes, R., Bovy, P. (2000) Importance of objectives in urban transit-network design. Transportation Research Record: Journal of the Transportation Research Board, 1735 (1), 25-34. DOI: $10.3141 / 1735-04$

12. TCRP Report 19. (1996) Guidelines for the Location and Design of Bus Stops. Transit Cooperative Research Program, Washington, D.C.

13. Ceder, A., Prashker, J. N., Stern, J. I. (1983) An algorithm to evaluate public transportation stops for minimizing passenger walking distance. Applied Mathematical Modeling, 7(1), 19-24. DOI: 10.1016/0307-904X(83)90158-0.

14. Bowerman, R., Hall, B., Calamai, P. (1995) A multi-objective optimization approach to urban school bus routing: Formulation and solution method. Transportation Research Part A: Policy and Practice, 29(2), 107-123. DOI:10.1016/0965-8564(94)E0006-U

15. Vuchic, V. R., Newell, G. F. (1968) Rapid transit interstation spacings for minimum travel time. Transportation Science, 2(4), 289-396. DOI:10.1287/trsc.2.4.303.

16. Fernandez, R. (1988) An expert system for the preliminary design and location of high-capacity busstops. Traffic Engineering and Control, 34(11), 533-539. https://trid.trb.org/View/384685

17. Furth, P., Rahbee, A. B. (2000) Optimal bus stop spacing through dynamic programming and geographic modeling. Transportation Research Record: Journal of the Transportation Research Board, 1731(1), 15-22. DOI: 10.3141/1731-03.

18. Murray, A. T. (2001) Strategic analysis of public transport coverage. Socio-Economic Planning Sciences, 35(3), 175-188. DOI: 10.1016/S0038-0121(01)00004-010.1016/S0038-0121(01)00004-0

19. Lao, Y., Liu, L. (2009) Performance evaluation of bus lines with data envelopment analysis and geographic information systems. Computers, Environment and Urban Systems, 33(4), 247-255. DOI: 10.1016/j.compenvurbsys.2009.01.005.

20. Delmelle, E., Li, S., Murray, A. T. (2012) Identifying bus stop redundancy: A GIS-based spatial optimization approach. Computers Environment and Urban Systems, 36(5), 445-455. DOI: 10.1016/j.compenvurbsys.2012.01.002.

21. Peng, H., Zhu, Y. (2013) Intercity train operation schemes based on passenger flow dynamic assignment. Journal of Transportation Systems Engineering and Information Technology, 13(1), 111-117. DOI: 10.1016/S1570-6672(13)60094-X.

22. Bai, H., Dong, R., Wang, K. (2014) Dynamic optimizing of bus average departure interval on network based on passenger flow information in time-space. In: 14th COTA International Conference of Transportation Professionals, 2014, Changsha, China.

23. Barrena, E., Canca, D., Coelho, L. C., Laporte, G. (2014) Single-line rail rapid transit timetabling under dynamic passenger demand. Transportation Research Part B: Methodological, 70, 134-150, DOI: $10.1016 /$ j.trb.2014.08.013.

24. Otto, B., Boysen, N. (2014) A dynamic programming based heuristic for locating stops in public transportation networks. Computers \& Industrial Engineering, 78, 163-174. DOI: 10.1016/j.cie.2014.10.011.

25. Tirachini, A. (2014) The economics and engineering of bus stops: Spacing, design and congestion. Transportation Research Part A, 59 ,37-57. DOI: 10.1016/j.tra.2013.10.010.

26. Jamili, A., Aghaee, M. P. (2015) Robust stop-skipping patterns in urban railway operations under traffic alteration situation. Transportation Research Part C: Emerging Technologies, 61, 63-74. DOI: 10.1016/j.trc.2015.09.013.

27. Gerami Matin, A., Vatani Nezafat, R., Golroo, A. (2017) A comparative study on using meta-heuristic algorithms for road maintenance planning: Insights from field study in a developing country. Journal of Traffic and Transportation Engineering (English Edition), 4(5), 477-486. DOI: 10.1016/j.jtte.2017.06.004

28. Bargegol, I., Ghorbanzadeh, M., Ghasedi, M., Rastbod,M. (2017) Evaluation of effective factors on travel time in optimization of bus stops placement using genetic algorithm. IOP Conference Series: Materials Science and Engineering, 245. DOI: 10.1088/1757-899X/245/4/042002\%20.

29. Highway Capacity Manual (HCM) (2010) National Research Council, Washington, DC. 